\title{
RCM: A new model accounting for the non-linear chloride binding isotherm and the non-equilibrium conditions between the free- and bound-chloride concentrations
}

Citation for published version (APA):

Spiesz, P. R., Ballari, M. M., \& Brouwers, H. J. H. (2012). RCM: A new model accounting for the non-linear chloride binding isotherm and the non-equilibrium conditions between the free- and bound-chloride concentrations. Construction and Building Materials, 27(1), 293-304.

https://doi.org/10.1016/j.conbuildmat.2011.07.045

DOI:

10.1016/j.conbuildmat.2011.07.045

Document status and date:

Published: 01/01/2012

Document Version:

Publisher's PDF, also known as Version of Record (includes final page, issue and volume numbers)

\section{Please check the document version of this publication:}

- A submitted manuscript is the version of the article upon submission and before peer-review. There can be important differences between the submitted version and the official published version of record. People interested in the research are advised to contact the author for the final version of the publication, or visit the DOI to the publisher's website.

- The final author version and the galley proof are versions of the publication after peer review.

- The final published version features the final layout of the paper including the volume, issue and page numbers.

Link to publication

\footnotetext{
General rights

- You may freely distribute the URL identifying the publication in the public portal. follow below link for the End User Agreement:

www.tue.nl/taverne

\section{Take down policy}

If you believe that this document breaches copyright please contact us at:

openaccess@tue.nl

providing details and we will investigate your claim.
}

Copyright and moral rights for the publications made accessible in the public portal are retained by the authors and/or other copyright owners and it is a condition of accessing publications that users recognise and abide by the legal requirements associated with these rights.

- Users may download and print one copy of any publication from the public portal for the purpose of private study or research.

- You may not further distribute the material or use it for any profit-making activity or commercial gain

If the publication is distributed under the terms of Article $25 \mathrm{fa}$ of the Dutch Copyright Act, indicated by the "Taverne" license above, please 


\title{
RCM: A new model accounting for the non-linear chloride binding isotherm and the non-equilibrium conditions between the free- and bound-chloride concentrations
}

\author{
P. Spiesz *, M.M. Ballari, H.J.H. Brouwers \\ Department of the Built Environment, Eindhoven University of Technology, P.O. Box 513, 5600 MB Eindhoven, The Netherlands
}

\section{A R T I C L E I N F O}

Article history:

Received 18 April 2011

Received in revised form 20 July 2011

Accepted 20 July 2011

Available online 5 October 2011

\section{Keywords:}

Concrete

Chloride

Diffusion

Transport properties

Modelling

\begin{abstract}
A B S T R A C T
In this paper a new theoretical model for the Rapid Chloride Migration test is presented. This model accounts for the non-linear chloride binding isotherm and the non-equilibrium conditions between the free- and bound-chloride concentrations in concrete. The new system of equations is solved numerically and compared to a simplified analytical solution, revealing a good agreement. Subsequently, numerical simulations are applied to experimental data on chloride concentration profiles in concrete obtained elsewhere. The binding parameters, the chloride mass transfer coefficient and the effective diffusion coefficient of chloride are estimated with these simulations. The non-linear binding coefficients correspond well to experimental data found in literature. The chloride mass transfer coefficient reveals a tendency to decrease in time during the application of electrical field across a concrete sample. The effective chloride diffusion coefficient $\left(D_{\text {eff }}\right)$ obtained in the present study is found to be in line with data obtained elsewhere. Finally, it is demonstrated that the values of the diffusion coefficient computed from the Rapid Chloride Migration test in the traditional way are overestimated.
\end{abstract}

(c) 2011 Elsevier Ltd. All rights reserved.

\section{Introduction}

In view of problems with chloride-induced corrosion of reinforcing steel, there is a need for quantified information on chloride transport properties in concrete. Thus, a reliable prediction model for chloride ingress into the concrete cover is considered as the key point for an assessment of the long-term behaviour of concrete exposed to sea water or de-icing salts.

A number of laboratory testing methods (both long- and shortterm) have been developed to quantify the chloride transport in concrete. The long-term methods, however, are usually not preferred from the practical point of view because they are laborious, time consuming and costly.

To overcome these disadvantages, an accelerated test - the Rapid Chloride Migration test (RCM), also known as CTH or RMT, has been developed by Tang [1] and standardized as NT Build 492 [2]. Within the European DuraCrete report [3] the output value of the RCM test: $D_{R C M}$ - chloride diffusion coefficient in non-steady-state conditions (also termed chloride migration coefficient) - has been introduced into the service life model for concrete, which has lately resulted in even higher popularization of the test method. An exemplary application of the $D_{R C M}$

\footnotetext{
* Corresponding author. Tel.: +31 (0) 40247 5904; fax: +31 (0) 402438595 .

E-mail address: p.spiesz@tue.nl (P. Spiesz).
}

coefficient for the service life design of a concrete structure can be found e.g. in [4]. The application of the $D_{R C M}$ coefficient for service life modelling of concrete puts strict requirements on the test such as reliability or repeatability of results. Nevertheless, 12 years after the standardization of the RCM test, there are still some concerns regarding its theoretical background and these will be addressed in this paper.

The main principle of migration tests is to quantify the diffusivity of chloride in liquid-saturated concrete by correlating the diffusion coefficient with electrochemical parameters. This is accomplished by using the Nernst-Planck equation as proposed e.g. in $[1,5,6]$. The equation can be solved for steady-state conditions or for transient state, yielding the effective chloride diffusion coefficient $\left(D_{\text {eff }}\right)$ or the apparent diffusion coefficient $\left(D_{\text {app }}\right)$ respectively. However, foregoing research presented in [1,7-9] unveils that the $D_{\text {app }}$ obtained from non-steady state diffusion tests and the $D_{R C M}$ from the migration tests are correlated, but the reported $D_{R C M}$ is usually larger than the $D_{a p p}$, although both diffusion coefficients should be the same if correct theoretical models are applied. Also in [10] the apparent diffusion and migration coefficients are compared and revealed to be different, but the used migration test method was not the RCM.

The analysis of the RCM test presented in this paper shows that the commonly adopted simplified model for the chloride migration needs improvement and therefore the equations that have been developed in order to compute the value of the $D_{R C M}$ should be 


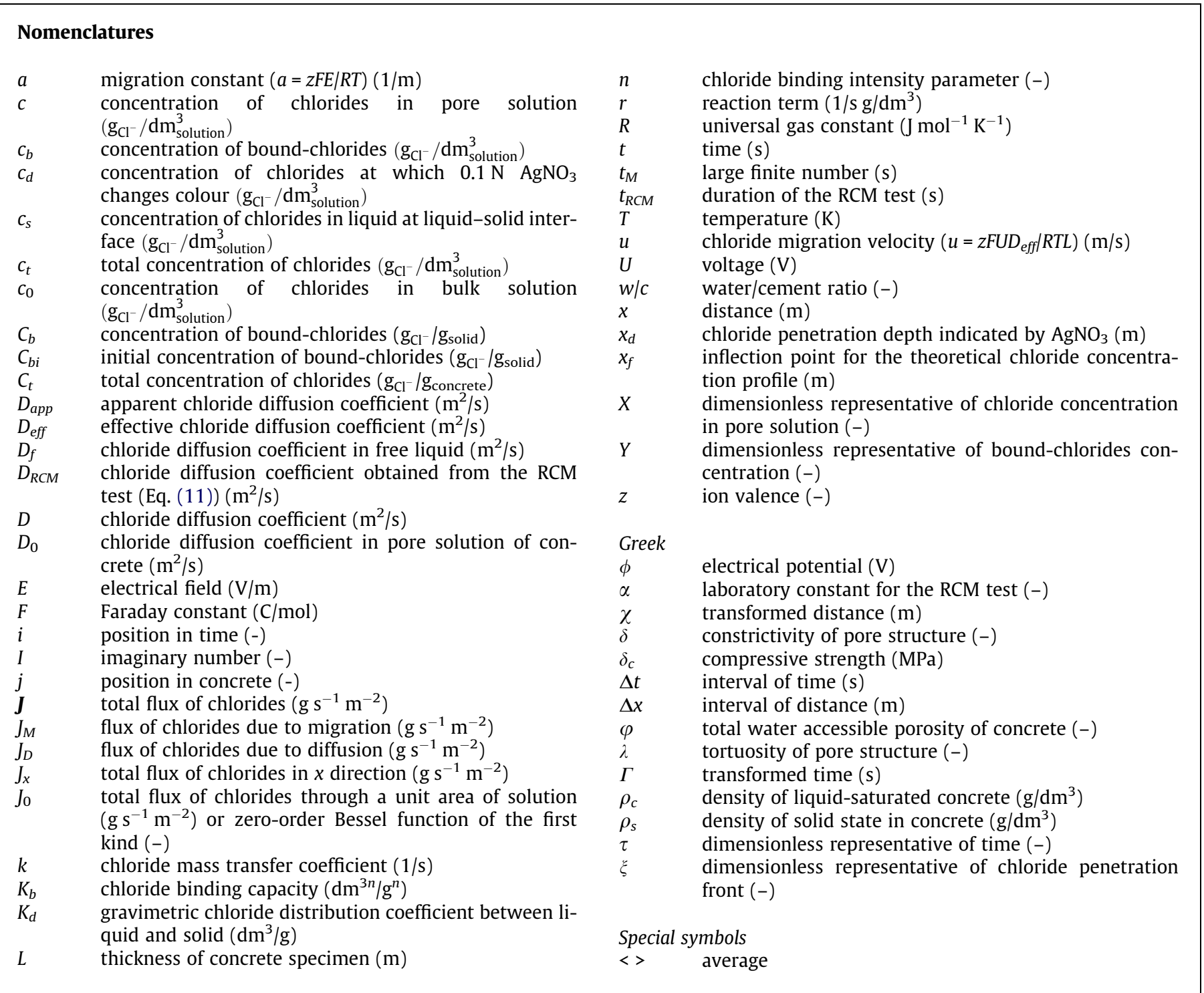

treated carefully. Thus, the objective of this study is to propose an improved chloride transport model in concrete for the non-steadystate migration test. This new model, modified with the assumptions of the non-linear chloride binding isotherm and non-equilibrium conditions between chloride concentrations in the pore solution and in the solid phase, should be self-consistent and predict the transport of chloride in concrete better.

\section{The Rapid Chloride Migration test (NT Build 492 [2])}

\subsection{Experimental procedure of the RCM test}

The RCM test is a non-steady-state test, based on the ionic migration induced by an external voltage applied across a concrete specimen saturated with $\mathrm{Ca}(\mathrm{OH})_{2}$-saturated water solution. The schematic and actual test set-ups are presented in Fig. 1. Due to the potential difference applied between the electrodes, chloride ions move from the upstream solution $\left(\sim 2 \mathrm{~mol} / \mathrm{dm}^{3} \mathrm{NaCl}\right.$ solution, hence the chloride concentration in the upstream solution is $70.9 \mathrm{~g} / \mathrm{dm}^{3}$ ), through the concrete specimen, towards the downstream solution $(\mathrm{NaOH}-$ $0.3 \mathrm{~mol} / \mathrm{dm}^{3}$ ). The duration of the test yields between 6 and $96 \mathrm{~h}$ (depending on the quality of the concrete expressed in terms of the ini- tial current value when the external voltage is set to $30 \mathrm{~V}$ ). Afterwards, the specimen is split and sprayed with $\mathrm{AgNO}_{3}$ - a colourimetric indicator for chlorides. Finally, the chloride penetration depth is measured and based on this value the $D_{R C M}$ is calculated from the mathematical formulas presented in the next Section of this paper.

\subsection{Current theoretical model of the RCM test}

The general continuity equation for the chloride transport in concrete presents as follows [11]:

$\frac{\partial c_{t}}{\partial t}+\boldsymbol{u} \nabla c+\nabla \cdot \boldsymbol{J}=r$

where $c_{t}$ is the total chloride concentration in concrete, $\boldsymbol{u}$ the velocity of chloride ion, $c$ the concentration of chlorides in pore solution of concrete, $\boldsymbol{J}$ the total flux of chlorides and $r$ is the reaction term.

As mentioned before, the chloride ions in migration experiments are accelerated by the electrical field in order to penetrate the saturated concrete specimen with a much higher rate in comparison to diffusion due to a concentration gradient. The total flux of chlorides for a combined process of diffusion and migration of ions through saturated and uncharged porous medium is given by the Nernst-Planck equation $[1,5,6]$ : 

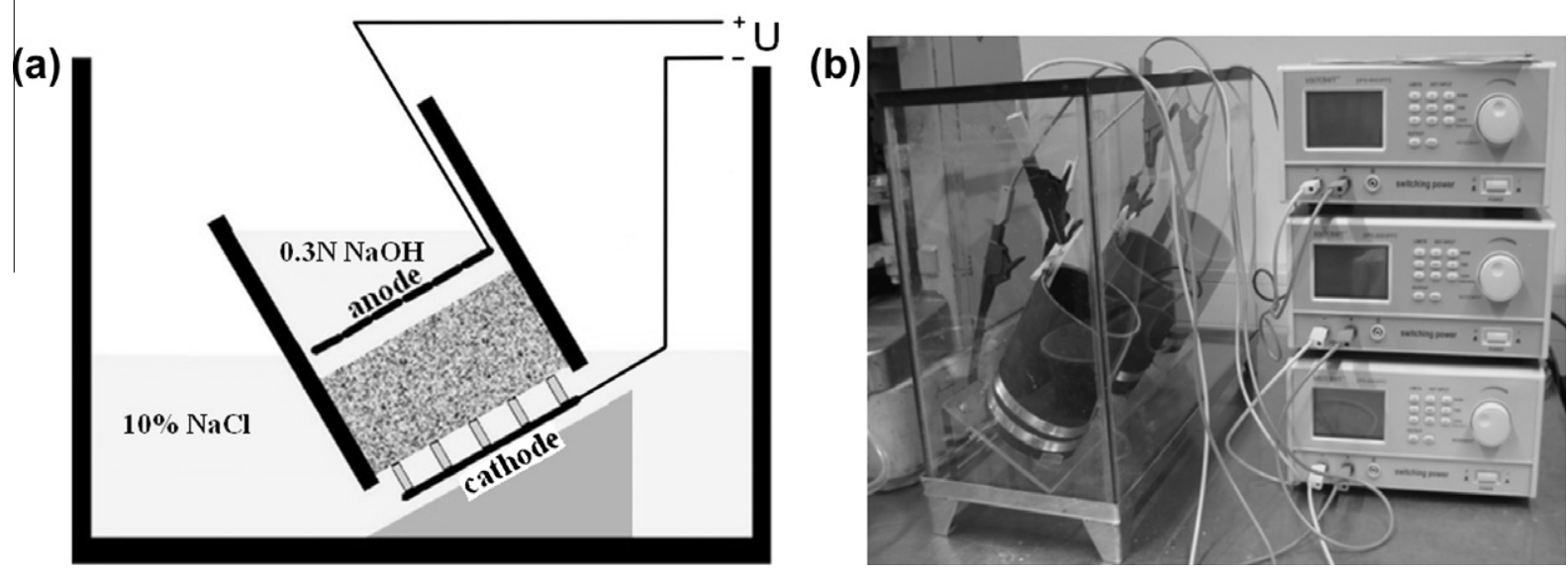

Fig. 1. Rapid Chloride Migration test set-up: (a) schematic and (b) actual.

$J_{x}=-D\left(\frac{\partial c}{\partial x}-\frac{z F}{R T} c \frac{\partial \phi}{\partial x}\right)$

where $D$ is the diffusivity of chloride and $\phi$ is the electrical potential in the direction of $x$.

Simplifying the Nernst-Planck equation (Eq. (2)) with the assumption of a constant electrical field distribution across the concrete sample, the following equation for the total flux of chlorides in concrete is given [1]:

$J_{x}=J_{D}+J_{M}=-D\left(\frac{\partial c}{\partial x}-\frac{z F E}{R T} c\right)$,

where $J_{D}$ is the flux of chlorides due to diffusion, $J_{M}$ the flux of chlorides due to migration and $E$ is the electrical field $(E=U / L)$.

Inserting Eq. (3) into the continuity equation (Eq. (1)) and assuming: (a) the convection term equal to zero (no pressure gradients during the process); (b) zero reaction term (no change in mass due to reaction considering the whole system) and (c) the total chloride concentration $c_{t}$ defined as $c_{t}=c+c_{b}$, the following equation is derived for the chloride transport in concrete in nonsteady state conditions [1]:

$\frac{\partial c}{\partial t}=-\frac{\partial J_{0}}{\partial x}=\frac{D_{0}}{1+\frac{\partial c_{b}}{\partial c}}\left(\frac{\partial^{2} c}{\partial x^{2}}-\frac{z F E}{R T} \frac{\partial c}{\partial x}\right)=D_{R C M}\left(\frac{\partial^{2} c}{\partial x^{2}}-\frac{z F E}{R T} \frac{\partial c}{\partial x}\right)$

It is worth to emphasize that in Eq. (4) the linear chloride binding isotherm is introduced in the $D_{R C M}$ coefficient due to the assumption of $\partial c_{b} / \partial c=$ constant. This assumption is questionable because the binding of chlorides in concrete is non-linear, therefore the term $\partial c_{b} / \partial c$ does not have a constant value. Additionally, the above equation represents equilibrium conditions between free- and bound-chlorides concentrations. These issues will be addressed later in this paper.

By solving Eq. (4) while applying the following initial and boundary conditions for a semi-infinite medium [1]:

$$
\begin{aligned}
& c=0, \quad x>0, \quad t=0, \\
& c=c_{0}, \quad x=0, \quad t>0, \\
& c=0, \quad x \rightarrow \infty, \quad t=t_{m},
\end{aligned}
$$

where $c_{0}$ is the concentration of chlorides in the external bulk solution, the following analytical solution is obtained [1]:

$c(x, t)=\frac{c_{0}}{2}\left[e^{a x} \operatorname{erfc}\left(\frac{x+a D_{R C M} t}{2 \sqrt{D_{R C M} t}}\right)+\operatorname{erfc}\left(\frac{x-a D_{R C M} t}{2 \sqrt{D_{R C M} t}}\right)\right]$,

where $a=z F E / R T$ and erfc is the complement to the error function: $\operatorname{erfc}=(1-$ erf $)$.
Assuming that the electrical field and the chloride penetration depth are large enough, the $e^{a x}$ erfc term on the right side tends to zero, thus Eq. (6) can be simplified to [1]:

$c(x, t)=\frac{c_{0}}{2} \operatorname{erfc}\left(\frac{x-a D_{R C M} t}{2 \sqrt{D_{R C M} t}}\right)$.

In Fig. 2 the solution of Eq. (7) is plotted for different $t$, and as can be seen in this figure, the free-chloride concentration changes rapidly from the bulk concentration $\left(c_{0}\right)$ to 0 within a short distance in concrete depth.

It can be found from Eq. (7) that each profile has an inflection point at $x_{f}$ (see Fig. 2), given in [1] as:

$x_{f}=\frac{z F E}{R T} D_{R C M} t$.

Nevertheless, because the value of $x_{f}$ is difficult to determine experimentally, $x_{d}$ is introduced, representing the chloride penetration indicated by using a colourimetric method. The following relationship between $x_{f}$ and $x_{d}$ is obtained in [1]:

$x_{f}=x_{d}-\alpha \sqrt{x_{d}}$,

$\alpha=2 \sqrt{\frac{R T L}{z F U}} \times \operatorname{erf}^{-1}\left(1-\frac{2 c_{d}}{c_{0}}\right)$,

where $\alpha$ is the laboratory constant, $c_{d}$ is the chloride concentration at which the colourimetric indicator changes the colour $(0.07 \mathrm{~mol} /$

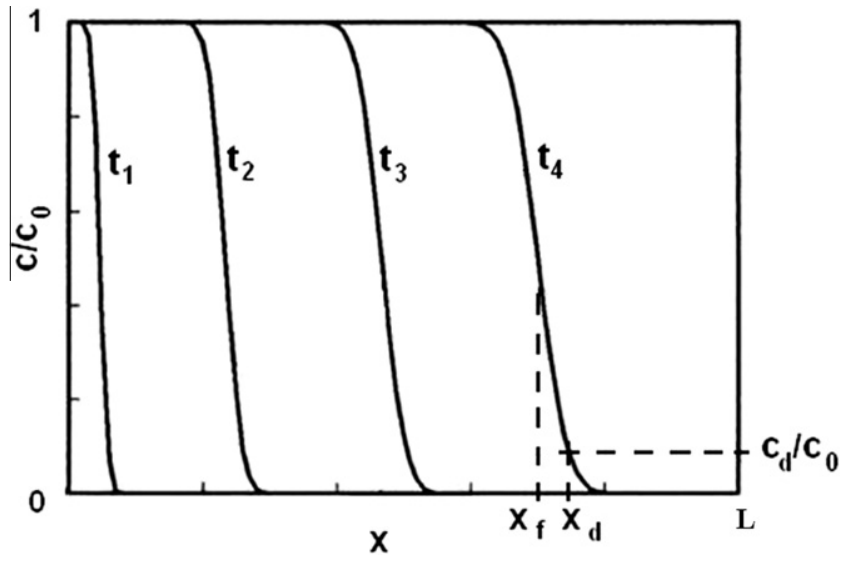

Fig. 2. Theoretical free-chloride concentration profiles in concrete after the RCM test [1]. 
$\mathrm{dm}^{3}$ or $2.48 \mathrm{~g} / \mathrm{dm}^{3}$ ). Inserting Eq. (9) into Eq. (8) and solving for the $D_{R C M}$ gives as follows [1]:

$D_{R C M}=\frac{R T L}{z F U} \times \frac{x_{d}-\alpha \sqrt{x_{d}}}{t_{R C M}}$.

The output of the test $-D_{R C M}$ is a chloride ion transport parameter in concrete, expressed in $\mathrm{m}^{2} / \mathrm{s}$ and $t_{R C M}$ is the final duration of the migration test.

\subsection{Verification of the traditional theoretical model for the RCM test}

As mentioned earlier, an abrupt free-chloride concentration profile (see Fig. 2) represents the solution of the chloride transport model developed in [1]. However, in practice it is very difficult to measure the free-chloride concentration profile in concrete, so usually only the total chloride concentration is measured. Although the theoretical free- and total chloride concentration profiles are not equal to each other when bound-chlorides are present in concrete, they hypothetically should have the same shape if the assumptions of linear chloride binding isotherm and instantaneous equilibrium in the traditional RCM model were correct (see Eq. (4)).

Several researchers have presented the experimental total chloride concentration profiles measured in concrete after the migration tests $[1,8,9,12-16]$. Table 1 shows the concrete mix proportions and the RCM test conditions for which the chloride concentration profiles were measured by Stanish [12] and Yuan [9]. One of these RCM profiles [9] and an additional natural diffusion test profile (42 days exposure to chlorides), both measured for the same concrete (C4 in Table 1 ), are shown in Fig. 3. Clearly, the reported gradual experimental profiles after the RCM test are much different in shape in comparison to the theoretical 'tsunami' profile presented in Fig. 2, and very similar in fact to chloride profiles measured in concrete after natural diffusion exposure to chlorides. This difference between the theory and the experimental measurements gives evidence that the current chloride transport model for the RCM test unsatisfactorily describes the real process. Therefore, the $D_{R C M}$ calculated based on the Eq. (11) should be treated carefully.

Tang in [1] gives a few possible explanations for the difference between the theoretical and experimental chloride profiles, such as (a) different pore distribution resulting in different penetration front; (b) reaction kinetics which changes the shape of the profile without changing the penetration depth or (c) the influence of other ions on the chloride binding. These are sound arguments, but the efforts taken so far in order to develop a chloride migration

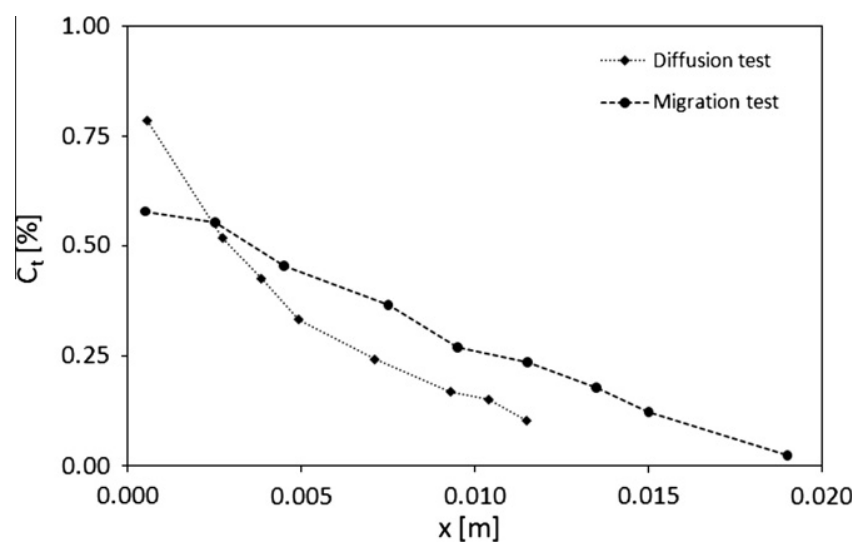

Fig. 3. Experimental total chloride concentration profile in concrete after the migration and diffusion tests for concrete C4 [9].

model which predicts well the experimental profile (e.g. including the reaction kinetics or developing multi-species models for a combined diffusion-migration process) were unsatisfying. Furthermore, other possible explanations can be added to the list.

As previously stated, the chloride concentration profile shown in Fig. 2 results from Eq. (7), in which the assumptions of the linear binding isotherm and equilibrium between free- and bound-chlorides are introduced. However, as will be explained in the next Section, chloride binding in concrete is a non-linear process and the equilibrium between free- and bound-chlorides cannot be achieved within such a short period of time as the duration of the RCM test. Therefore, the authors present a new simplified chloride transport model, which can properly predict the behaviour of chlorides migrating into concrete. This new model includes among others the non-linear binding isotherm and non-equilibrium conditions between free- and bound-chlorides.

\section{Chloride binding}

When chloride ions penetrate concrete, part of them can be captured and immobilized by the hydration products of cement. This process of interaction between the chloride ions and cement hydrates - so-called chloride binding - can take place in two ways: by chemical reaction (with calcium aluminate hydrates) or physical adsorption (on the surface of the $\mathrm{C}-\mathrm{S}-\mathrm{H}$ gel). Nevertheless, it is very difficult in practice to distinguish between the chlorides

Table 1

Testing conditions and properties of concrete.

\begin{tabular}{|c|c|c|c|c|c|}
\hline $\begin{array}{l}\text { Concrete code } \\
\text { Reference }\end{array}$ & $\begin{array}{l}\text { C1 } \\
{[12]}\end{array}$ & $\begin{array}{l}\mathrm{C} 2 \\
{[12]}\end{array}$ & $\begin{array}{l}\text { C3 } \\
{[9]}\end{array}$ & $\begin{array}{l}\text { C4 } \\
{[9]}\end{array}$ & $\begin{array}{l}\text { C5 } \\
{[9]}\end{array}$ \\
\hline $\mathrm{w} / \mathrm{c}$ & 0.35 & 0.45 & 0.35 & 0.48 & 0.60 \\
\hline $\begin{array}{l}\text { Cement type } \\
\left(\mathrm{kg} / \mathrm{m}^{3}\right)\end{array}$ & $\begin{array}{l}\text { T10 } \\
418\end{array}$ & $\begin{array}{l}\mathrm{T} 10 \\
362.5\end{array}$ & $\begin{array}{l}\text { Cem I } 52.5 \mathrm{~N} \\
400\end{array}$ & $\begin{array}{l}\text { Cem I } 52.5 \mathrm{~N} \\
380\end{array}$ & $\begin{array}{l}\text { Cem I } 52.5 \mathrm{~N} \\
363\end{array}$ \\
\hline Water $\left(\mathrm{kg} / \mathrm{m}^{3}\right)$ & 146 & 163 & 140 & 182 & 218 \\
\hline Coarse aggregates $\left(\mathrm{kg} / \mathrm{m}^{3}\right)$ & 1025 & 1025 & 1281 & 1217 & 1162 \\
\hline Sand $\left(\mathrm{kg} / \mathrm{m}^{3}\right)$ & 695 & 698 & 660 & 627 & 599 \\
\hline Additives & Air entrainer, superplasticizer & Air entrainer & Water reducer & - & - \\
\hline$\sigma_{\mathrm{c}}(56$ days) $(\mathrm{MPa})$ & 52 & 33 & 81.7 & 46.7 & 37.9 \\
\hline Age (months) & $12-18$ & $12-18$ & 2 & 2 & 2 \\
\hline$t_{\mathrm{RCM}}(\mathrm{h})$ & 6,9 and 18 & 6,9 and 18 & 24 & 24 & 24 \\
\hline$\rho_{\mathrm{c}}\left(\mathrm{kg} / \mathrm{m}^{3}\right)$ & 2577 & 2553 & 2637 & 2608 & 2584 \\
\hline$\rho_{\mathrm{s}}\left(\mathrm{kg} / \mathrm{m}^{3}\right)$ & 2601 & 2606 & 2665 & 2661 & 2643 \\
\hline $\mathrm{U}(\mathrm{V})$ & 60 & 60 & 35 & 25 & 20 \\
\hline$c_{0}\left(\mathrm{~g} / \mathrm{dm}^{3}\right)$ & 70.9 & 70.9 & 70.9 & 70.9 & 70.9 \\
\hline $\mathrm{L}(\mathrm{m})$ & 0.05 & 0.05 & 0.05 & 0.05 & 0.05 \\
\hline$\varphi(\%)$ & 11.3 & 14.3 & 10.2 & 14.1 & 15 \\
\hline
\end{tabular}


physically or chemically bound in concrete, thus the total amount of bound-chlorides is usually investigated (e.g. in so called equilibrium method [1]). It is important to emphasize that only the freechlorides are able to penetrate the concrete, which in time may lead to the depassivation of steel rebars, while bound-chlorides are considered immobilized and harmless to the reinforcement. Many extensive reviews regarding the binding of chlorides in concrete can be found in literature e.g. in [17-19].

During the migration test not only the chlorides but also other ions, such as $\mathrm{OH}^{-}$, are migrating. This can lead to changes in the $\mathrm{pH}$ of the pore solution in concrete and some researchers $[1,17,20]$ stated that binding of chlorides in concrete depends on the value of $\mathrm{pH}$. Nevertheless, for sake of simplicity, the amount of bound-chlorides in models for the transport of chloride in concrete is assumed as independent from the changes in $\mathrm{pH}$.

\subsection{Non-linear binding of chlorides in concrete}

The amount of bound-chlorides increases non-linearly with an increase of the free-chlorides concentration and this relationship is most often described using chloride binding isotherms. Among the binding isotherms the most commonly used are the isotherms of Langmuir, Freundlich and BET. The linear chloride binding isotherm does not predict in a proper way the relationship between bound- and free-chlorides: it can be applicable only within a limited range of free-chlorides concentration [1].

Tang in [1] shows that the experimental data for the chloride binding in concrete obeys the Freundlich isotherm in free-chloride concentrations in the range of $0.01-1 \mathrm{~mol} / \mathrm{dm}^{3}(0.35-35.45 \mathrm{~g} /$ $\mathrm{dm}^{3}$ ), while the binding obeys the Langmuir isotherm at low $\mathrm{Cl}^{-}$ concentrations $\left(<0.05 \mathrm{~mol} / \mathrm{dm}^{3}\right)$. The chloride binding data presented in [17] shows that even for a higher chloride concentration (up to $3 \mathrm{~mol} / \mathrm{dm}^{3}$ ) the Freundlich equation (Eq. (12)) describes the binding correctly. During the RCM test, the concentration of chlorides in the bulk solution yields $2 \mathrm{~mol} / \mathrm{dm}^{3}$, thus the Freundlich isotherm can adequately represent the chloride binding.

The Freundlich isotherm is governed by the following equation:

$C_{b}=K_{b} c^{n}$,

where $C_{b}$ is the concentration of bound-chlorides, $K_{b}$ the chloride binding capacity of concrete and $n$ is the binding intensity parameter.

$K_{b}$ and $n$ are empirical coefficients from the linear log-log regression analysis of the chloride binding isotherms. The values of $K_{b}$ and $n$ for various cement pastes and one mortar, retrieved from $[1,17]$ and recalculated to the units of concentrations used in this paper, are summarized in Table 2 . It can be noticed that the presented values of $K_{b}$ are much smaller for mortar than for cement pastes. This can be directly related to the volume of cement hydration products, which are capable to bind chlorides. This volume is much larger for cement pastes than for mortars, due to a large fraction of volume (about 3/4) occupied by small inert aggregates in the latter. Indeed, as can be seen in Table 2 , the $K_{b}$ is about four times larger for pastes than for mortar. In concrete the paste constitutes about $1 / 5$ of its volume, therefore the value of $K_{b}$ is expected to be five times lower compared to the paste samples because only the cement paste is able to bind chlorides. When analyzing the values of the binding capacity $K_{b}$ in Table 2 , one can notice that it holds within the range of $2.13-2.58\left(\mathrm{dm}^{3 n} / \mathrm{g}^{n}\right)$ for Cem I (EN 197) and Cem T20 (Canadian standard: CSA A300098) pastes. For the paste of Cem T10 (CSA A3000-98), the binding capacity is increased. This is due to an increased $C_{3} A$ content in Cem T10 [17], which hydration products can bind more chlorides. When replacing $25 \%$ of the cement paste with blast furnace slag (GGBS) the binding capacity is increased to $2.65-2.68\left(\mathrm{dm}^{3 n} / \mathrm{g}^{n}\right)$ which shows that slag-blended cements and their hydration products can bind more chlorides in comparison to the pure Cem I and Cem T20 pastes. On the other hand, when fly ash or silica fume are replacing the cement, the binding capacity is reduced. Similar conclusions can be also found in [21]. It can be also noticed that the $K_{b}$ for the same paste diminishes in time, which can be explained by the densification of the microstructure due to the progressing hydration.

The value of the binding intensity $n$ for the pastes holds within the range of $0.31-0.45$ and from the data shown in Table 2 there are no clear trends regarding the influence of the age or the cement replacement on its value. However, the value of $n$ for mortar is larger than for pastes.

\subsection{Concentration non-equilibrium}

The liquid-solid system in concrete can be described as being composed of three zones: bulk liquid, stagnant liquid (the interface between the bulk liquid and the solid) and the solid state. When chloride ions are transferred from one phase (liquid) to another (solid) across an interface that separates the two, the resistance to mass transfer causes a concentration gradient in each phase [22]. Due to the limitations in the mass transfer through this interface, usually a certain time is required in order to achieve the equilibrium; therefore for a certain time there will be non-equilibrium conditions between the concentrations of chlorides in the pore solution and the concentration of chlorides in the interface.

Table 2

Chloride binding parameters - Freundlich isotherm.

\begin{tabular}{|c|c|c|c|c|c|}
\hline Reference & Material & Age (days) & $w / c$ & $K_{b}\left(\times 10^{-3} \mathrm{dm}^{3 n} / \mathrm{g}^{n}\right)$ & $n$ \\
\hline \multirow{4}{*}{ [1] } & Cem I paste & 42 & 0.4 & 2.14 & 0.41 \\
\hline & Cem I paste & 42 & 0.6 & 2.29 & 0.42 \\
\hline & Cem I paste & 42 & 0.8 & 2.24 & 0.43 \\
\hline & Cem I mortar (C:S:W = 1:2:0.4) & 42 & 0.4 & 0.53 & 0.52 \\
\hline \multirow{12}{*}{ [17] } & Cem T20 paste & 60 & 0.3 & 2.58 & 0.31 \\
\hline & Cem T20 paste & 60 & 0.5 & 2.40 & 0.34 \\
\hline & Cem T20 paste & 270 & 0.5 & 2.13 & 0.37 \\
\hline & Cem T10 paste & 60 & 0.5 & 2.97 & 0.37 \\
\hline & $92 \%$ Cem T20 + $8 \%$ silica fume & 60 & 0.3 & 1.22 & 0.36 \\
\hline & $92 \%$ Cem T20 + 8\% silica fume & 60 & 0.5 & 1.59 & 0.37 \\
\hline & $92 \%$ Cem T20 + $8 \%$ silica fume & 270 & 0.5 & 1.52 & 0.42 \\
\hline & $75 \%$ Cem T20 + $25 \%$ fly ash & 60 & 0.3 & 1.63 & 0.39 \\
\hline & $75 \%$ Cem T20 + 25\% fly ash & 60 & 0.5 & 2.63 & 0.40 \\
\hline & $75 \%$ Cem T20 + 25\% fly ash & 270 & 0.5 & 2.00 & 0.45 \\
\hline & $75 \%$ Cem T $20+25 \%$ GGBS & 60 & 0.3 & 2.68 & 0.30 \\
\hline & $75 \%$ Cem T20 + 25\% GGBS & 270 & 0.5 & 2.65 & 0.38 \\
\hline
\end{tabular}


Additionally, one can assume that there will be instantaneous equilibrium between the concentration of chlorides bound in the solid (cement paste) and the chlorides in the liquid-solid interface. Thus, such conditions can be described as non-equilibrium between the concentrations of chlorides in the bulk solution and bound-chlorides due to the liquid-solid mass transfer resistance.

From literature it is known that the equilibrium for chloride binding experiments in concrete can be achieved after 7 days [1] or 10-14 days [23] of exposure. For the diffusion tests, the assumption of equilibrium is acceptable since the chloride exposure period is sufficiently long. However, the duration of the RCM test usually amounts to $24 \mathrm{~h}$ and rarely varies from $6 \mathrm{~h}$ (for poor quality concrete) up to 4 days (for very good quality concrete). This fact is also pointed out in [14]. Therefore, during the migration process, equilibrium between free- and bound-chlorides concentrations cannot be achieved, which implies a necessity of the application of the $\mathrm{Cl}^{-}$ mass transfer rate. The mass transfer rate of chlorides from the pore solution, through the liquid-solid interface and towards the solid, is considered to be induced by a concentration gradient in these phases.

It is worth to mention that the $D_{a p p}$ obtained from diffusion tests (e.g. NT Build 443 [24]) and non-steady-state migration tests (NT Build 492 [2]) cannot be equal to each other because the assumption of equilibrium in their theoretical models is fulfilled for the diffusion tests, but is not valid for the RCM test.

\section{Non-linear chloride binding and non-equilibrium conditions during migration}

Sometimes researchers state that the interaction between chloride ions and concrete matrix can be ignored, since the application of an electrical field generates an ionic transport rate which is much faster than the kinetics of chemical reactions in concrete or that the exposure time to chloride solution during the RCM test is too short. In order to verify this statement, the presence of chloride binding during the RCM experiments is investigated in this Section by analyzing some literature data concerning the total chloride concentration profiles in concrete after the RCM test.

The measurements of chloride concentration profiles are conducted by flushing concrete dust (from dry-grounded layers of the material) in nitric acid in order to extract the chloride ions. Then the concentration of the extracted chlorides is measured by using a chloride-selective electrode or titration method. The measured value represents the total chloride concentration in the concrete sample $\left(C_{t}\right)$, thus consists of both: free- $(c)$ and boundchlorides $\left(C_{b}\right)$ :

$C_{t}=\frac{\varphi c+(1-\varphi) \rho_{s} C_{b}}{\rho_{c}}$,

where $\varphi$ is the water accessible porosity of concrete, $\rho_{s}$ the density of solid state of concrete and $\rho_{c}$ is the density of saturated concrete.

If there would be no chloride binding in concrete, Eq. (13) can be simplified to:

$C_{t}=\frac{\varphi c}{\rho_{c}}$.

During the migration process, the concentration of chlorides in the pore solution of concrete tends in time to the concentration in the bulk solution $\left(c \rightarrow c_{0}=70.9 \mathrm{~g} / \mathrm{dm}^{3}\right)$. Considering the absence of chloride binding in concrete during the migration test, the maximum chloride concentration for the concrete tested by Stanish [12] (Table 1 , concrete C2) amounts to $0.397 \%\left(\mathrm{~g}_{\mathrm{Cl}^{-}} / \mathrm{g}_{\text {concrete }}\right)$, as can be computed from Eq. (14). Nevertheless, as shown in Fig. 4, the measured maximum concentration, about $0.85 \%$ $\left(\mathrm{g}_{\mathrm{Cl}^{-}} / \mathrm{g}_{\text {concrete }}\right)$, exceeds this value substantially. This effect cannot

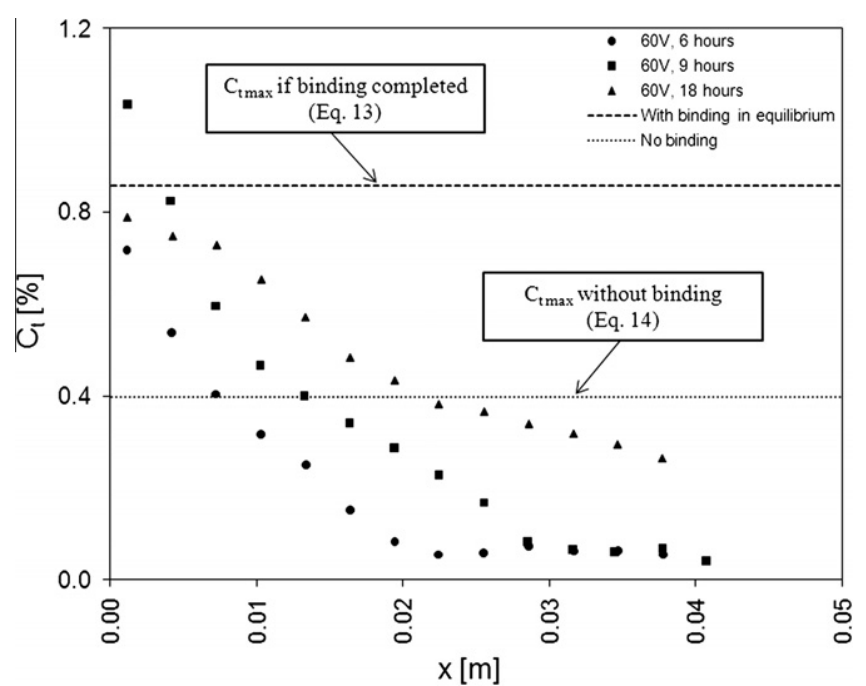

Fig. 4. Measured chloride concentration profiles [12] vs. theoretical maximum values.

be explained by a higher porosity than the one which was measured - for the $\mathrm{Cl}^{-}$concentration equal to $0.85 \%\left(\mathrm{~g}_{\mathrm{Cl}^{-}} / \mathrm{g}_{\text {concrete }}\right)$ the water accessible porosity $\varphi$ should exceed $26 \%$, which is an unrealistic value for a conventional concrete. Thus, the high total concentration of chlorides confirms the presence of chloride binding.

In order to analyze the presence of equilibrium between freeand bound-chlorides in concrete in the case when $c_{0}$ concentration is reached in the pore solution (see Fig. 2), the maximum boundchloride concentration $\left(C_{b}\right)$ is calculated from Eq. (12) for $K_{b}=0.6 \times 10^{-3}\left(\mathrm{dm}^{3 n} / \mathrm{g}^{n}\right)$ and $n=0.51\left(K_{b}\right.$ and $n$ extrapolated from Table 2 for concrete), and amounts to $0.0053\left(\mathrm{~g}_{\mathrm{Cl}^{-}} / \mathrm{g}_{\text {solid }}\right)$. This maximum bound-chloride concentration contributes $0.46 \%$ to the $C_{t}$, applying $\rho_{s}=2606 \mathrm{~g} / \mathrm{dm}^{3}$ (Table 1 ). Therefore, the maximum value of the total chloride concentration in concrete (Eq. (13)) implying equilibrium according to the non-linear binding isotherm (Eq. (12)), when the $c_{0}$ is reached in the pore solution, would yield $0.86 \%\left(\mathrm{~g}_{\mathrm{Cl}^{-}} / \mathrm{g}_{\text {solid }}\right)$, as appears in Fig. 4.

In the theoretical profile shown in Fig. 2 the maximum concentration of chlorides is reached in deeper layers of concrete too, while in the experimental chloride concentration profiles in Fig. 4 the concentration of chlorides decreases gradually along their whole length. Also in all the other experimental chloride profiles presented in $[1,8,9,12-16]$, the maximum $C_{t}$ is reached only at the surface of concrete. A possible explanation of this phenomenon can be the absence of equilibrium between free- and bound-chlorides, because if the free-chlorides are not bound instantaneously they have freedom to penetrate farther into the concrete.

\section{New chloride transport model for the non-steady-state migration}

The main idea of the new model proposed in this paper is an introduction of the non-linear chloride binding isotherm and non-equilibrium between free- and bound-chlorides concentrations, in the system based on the Nernst-Planck equation.

\subsection{Governing equations}

The simplified Nernst-Planck equation (Eq. (3)) is commonly used to describe ionic transport in porous medium due to combined actions of migration and diffusion. However, as showed in Fig. 5 [25], when a sufficiently large electrical field is applied across 
the concrete specimen, the flux of ions due to electrical migration $\left(J_{M}\right)$ dominates over the diffusion flux due to concentration gradients $\left(J_{D}\right)$. The fact that during the RCM test $U=10-60 \mathrm{~V}$ allows simplifying Eq. (3) to $J=J_{M}$.

When considering the total volume of concrete (solid state and pores completely saturated with liquid), the reaction term in the continuity equation (Eq. (1)) is normally set to zero. Nevertheless, when considering the liquid and solid phases separately, there is a non-zero reaction term, because the chlorides are transferred from one phase to another. It is assumed that the binding of chlorides takes place instantaneously at the surface of the hardened cement paste (i.e. reaction kinetics is not limiting the chloride transport so there is equilibrium between chloride concentration in liquid at liquid-solid interface and the concentration of bound-chlorides), but there is resistance to the mass transfer through the liquid-solid interface. This limitation in the mass transfer rate of chlorides is responsible for the non-equilibrium conditions in the system and is governed by the mass transfer coefficient $-k$. In other words, the mass transfer rate of chlorides is proportional to the deviation of the chlorides concentration in the bulk solution from the equilibrium concentration at the liquid-solid interface, as given by the Freundlich equation (Eq. (12)). Therefore, the mass transfer rate reads as follows:

$r=k\left(c-c_{s}\right)$,

where $c_{s}$ is the chloride concentration in liquid at liquid-solid interface.

Calculating $c_{s}$ from Eq. (12) and inserting it into Eq. (15) gives as follows [26]:

$r=k\left[c-\left(\frac{C_{b}}{K_{b}}\right)^{1 / n}\right]$.

From Eqs. (15) and (16) it can be noticed that the external chloride concentration is influencing the time needed to reach the equilibrium - for lower values of $c_{0}$ the initial difference between the $c_{0}$ and $c_{s}$ is lower as well, so the equilibrium between them can be reached faster.

When assuming: (a) no convection; (b) the diffusion rate negligible in comparison to the migration rate; (c) migration of chlorides only in the pore solution of concrete; (d) one dimensional and constant electrical field distribution across the concrete sample; (e) non-linear chloride binding isotherm; (f) non-equilibrium between free- and bound-chloride concentrations caused by the external liquid-solid mass transfer resistance, which is assumed to be the limiting step for the chloride transport; $(\mathrm{g})$ the binding parameters $\left(K_{b}\right.$ and $\left.n\right)$ constant during the migration and $(\mathrm{h})$ negligible effect of ionic interactions during the migration, the continuity equation (Eq. (1)) for liquid and solid phases respectively reads as follows [26]:

$\varphi \frac{\partial c}{\partial t}+u \frac{\partial c}{\partial x}=-k\left[c-\left(\frac{C_{b}}{K_{b}}\right)^{1 / n}\right]$,
$(1-\varphi) \rho_{s} \frac{\partial C_{b}}{\partial t}=k\left[c-\left(\frac{C_{b}}{K_{b}}\right)^{1 / n}\right]$,

where $u$ is the ionic migration velocity from Eq. (3), $u=D z F U / R T L$.

The boundary conditions pertaining to Eqs. (17) and (18) read as follows:

$$
\begin{gathered}
c(x=0, t)=c_{0}, \\
C_{b}(x, t=0)=C_{b i},
\end{gathered}
$$

where $C_{b i}$ is the initial bound-chloride concentration in concrete prior to migration test.

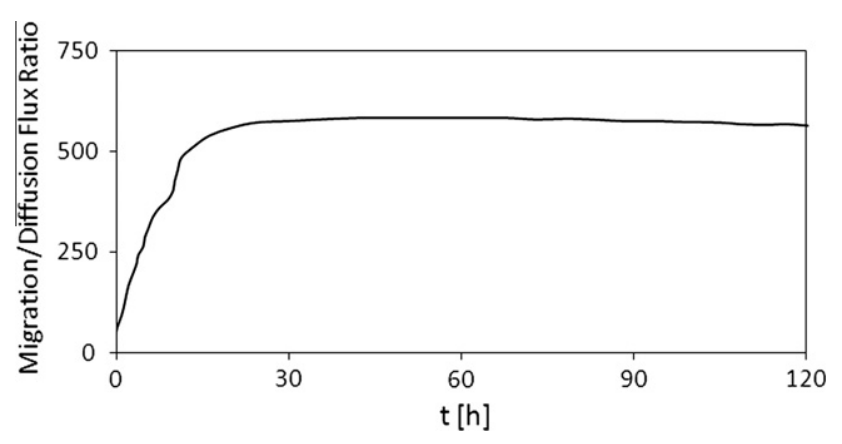

Fig. 5. Migration/diffusion flux ratio for $U \approx 10 \mathrm{~V}$ [25]

\subsection{Meaning of the diffusivity of chlorides adopted in the new model}

$D_{0}$ adopted in Tang's chloride transport model for the RCM test (Eq. (4)) represents the diffusion rate of chlorides through the pore solution in concrete and applies only to the liquid phase and not the entire volume of concrete. This coefficient can be defined as [27]:

$D_{0}=D_{f} \frac{\delta}{\lambda^{2}}$,

where $D_{f}$ is the diffusion coefficient of chlorides in free liquid (for $\mathrm{NaCl}$ solution at infinite dilution $D_{f}=2.03 \times 10^{-9}\left(\mathrm{~m}^{2} / \mathrm{s}\right), \delta$ the constrictivity of pore structure and $\lambda$ is the tortuosity of pore structure.

The constrictivity of the pore accounts for the fact that the cross section of a segment varies over its length whereas the tortuosity reflects how the pore structure is curved. These two parameters describing the pore structure are difficult to estimate for complicated porous systems (such as concrete), hence they are mostly used as theoretical parameters only.

When applying the diffusivity of chlorides in the pore solution of concrete to the total volume of concrete, the water (chloride) accessible porosity has to be included, which gives the so-called "effective" diffusivity [27]:

$D_{\text {eff }}=D_{f} \frac{\varphi \delta}{\lambda^{2}}=\varphi D_{0}$

$D_{\text {eff }}$ is commonly determined in steady-state migration or diffusion techniques. Both diffusion coefficients specified in Eqs. (20) and (21) are related only to the pore structure in concrete and are not dependent on binding.

On the other hand, the apparent diffusion coefficient $\left(D_{a p p}\right)$, influenced by sorption phenomena, is given by [27]:

$D_{a p p}=\frac{D_{e f f}}{\varphi+K_{d} \rho_{c}}$,

where $K_{d}$ is the gravimetric chloride distribution coefficient defined as:

$K_{d}=\frac{C_{b} \times(1-\varphi) \times \rho_{s}}{c \times \rho_{c}}$

The apparent diffusivity of chlorides $\left(D_{a p p}\right)$ can be derived from the non-steady-state diffusion tests (e.g. [24]). The diffusivity of chlorides obtained from the RCM test (Eqs. (4) and (11)) in intention should be equal to the $D_{a p p}$ for the same concrete. Nevertheless, as explained earlier in this paper, these two diffusion coefficients are not identical because the equilibrium between free- and bound-chlorides concentrations is achieved only during the diffusion tests.

Analyzing the new chloride transport model presented in this paper (see Section 5.1) it can be noticed that the binding term is not included in the diffusion coefficient (in contradiction to Eqs. 
(4) and (22)), which therefore is only related to the pore structure of concrete. Furthermore, the porosity of concrete is applied in the equations in order to split the total mass balance to liquid and solid. Thus, in view of coherency, this diffusion coefficient also takes the porosity into account. Therefore, the chloride diffusion coefficient adopted in the new chloride transport model is the effective diffusivity, as described in Eq. (21).

\subsection{Numerical solution}

In order to obtain the numerical solution of Eqs. (17) and (18) a forward discretization is performed (according to the scheme presented in Fig. 6) and reads as follows:

$$
\begin{aligned}
& \varphi \frac{C_{(i+1, j)}-c_{(i, j)}}{\Delta t}+u \frac{c_{(i+1, j+1)}-c_{(i+1, j)}}{\Delta x} \\
& =-k\left[c_{(i+1, j)}-\left(\frac{C_{b(i+1, j)}}{K_{b}}\right)^{1 / n}\right], \\
& (1-\varphi) \rho_{s} \frac{C_{b(i+1, j)}-C_{b(i, j)}}{\Delta t}=k\left[c_{(i, j)}-\left(\frac{C_{b(i, j)}}{K_{b}}\right)^{1 / n}\right],
\end{aligned}
$$

where $\Delta t$ is the interval of time, $i$ is the position in time, $(i=1 \ldots t)$ $\Delta t), \Delta x$ is the interval of distance, $j$ is the position in concrete $(j=1 \ldots L / \Delta x)$.

Solving Eqs. (24) and (25) for $c_{(i+1, j+1)}$ and $C_{b(i+1 j)}$ respectively, gives as follows:

$$
\begin{aligned}
c_{(i+1, j+1)}= & C_{(i+1, j)} \\
& -\frac{\Delta x}{u}\left(\varphi \frac{c_{(i+1, j)}-c_{(i, j)}}{\Delta t}+k\left(c_{(i+1, j)}-\left(\frac{C_{b(i+1, j)}}{K_{b}}\right)^{1 / n}\right)\right), \\
C_{b(i+1, j)}= & C_{b(i, j)}+\frac{\Delta t}{\rho_{s}(1-\varphi)} k\left(c_{(i, j)}-\left(\frac{C_{b(i, j)}}{K_{b}}\right)^{1 / n}\right),
\end{aligned}
$$

with the boundary conditions:

$$
\begin{aligned}
& c_{(i, j=1)}=c_{0}, \\
& C_{b(i=1, j)}=C_{b i} .
\end{aligned}
$$

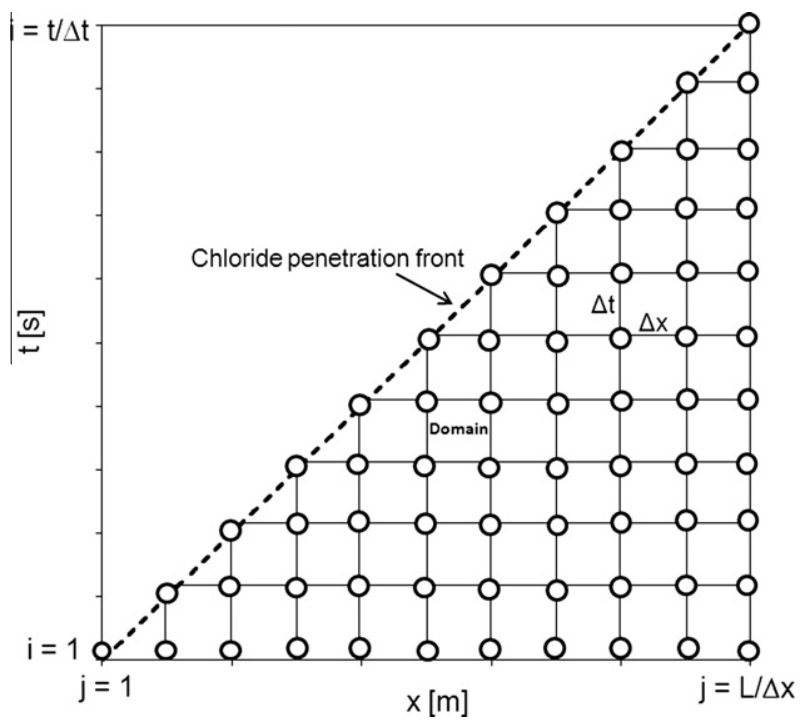

Fig. 6. Discretization scheme.

\subsection{Simplified analytical solution}

The system of Eqs. (17) and (18) can be solved analytically for zero initial chloride content in concrete $\left(C_{b i}=0\right)$ and $n=1$, i.e. linear binding isotherm and non-equilibrium conditions. In order to solve this system a transformation of variables is adopted as follows:

$\Gamma=t-\frac{\varphi x}{u}$,

$\chi=x$,

where $\chi$ is the transformed distance and $\Gamma$ is the transformed time. $\Gamma=0$ corresponds to the time needed for the chloride penetration front to attain a given position $\mathrm{x}$ in the concrete.

Transforming the derivatives of $t$ and $x$ and applying Eqs. (29) and (30) gives as follows:

$\frac{\partial}{\partial t}=\frac{\partial}{\partial \Gamma}$,

$\frac{\partial}{\partial x}=-\frac{\varphi}{u} \frac{\partial}{\partial \Gamma}+\frac{\partial}{\partial \chi}$

Inserting Eqs. (31) and (32) into Eqs. (17) and (18) gives for liquid and solid respectively:

$u \frac{\partial c}{\partial \chi}=-k\left(c-\frac{C_{b}}{K_{b}}\right), \quad 0<\chi<\psi$,

$(1-\varphi) \rho_{s} \frac{\partial C_{b}}{\partial \Gamma}=k\left(c-\frac{C_{b}}{K_{b}}\right), \quad 0<\Gamma<\frac{\psi \varphi}{u}$,

where the chloride penetration front $\psi=u t / \varphi$ and the pertaining boundary conditions (invoking $C_{b i}=0$ ) read as follows:

$c(\chi=0, \Gamma)=c_{0}$
$C_{b}(\chi, \Gamma=0)=0$.

Introducing the following dimensionless variables:

$X=\frac{c}{c_{0}}$, where $c_{0}$ is the maximum free-chloride concentration,

$0 \leqslant X \leqslant 1$

$Y=\frac{C_{b}}{K_{b} c_{0}}$, where $K_{b} c_{0}$ represents the maximum bound-chloride concentration, $0 \leqslant Y \leqslant 1$

$\xi=\frac{\chi k}{u}$

$\tau=\frac{\Gamma k}{K_{b}(1-\varphi) \rho_{s}}$,

into Eqs. (33) and (34) gives as follows:

$\frac{\partial X}{\partial \xi}=-(X-Y)$,

$\frac{\partial Y}{\partial \tau}=(X-Y)$,

with the following boundary conditions:

$X(\xi=0, \tau)=1$
$Y(\xi, \tau=0)=0$.

The analytical solution of Eqs. (40) and (41) applying the boundary conditions (Eq. (42)) reads as follows [11]: 


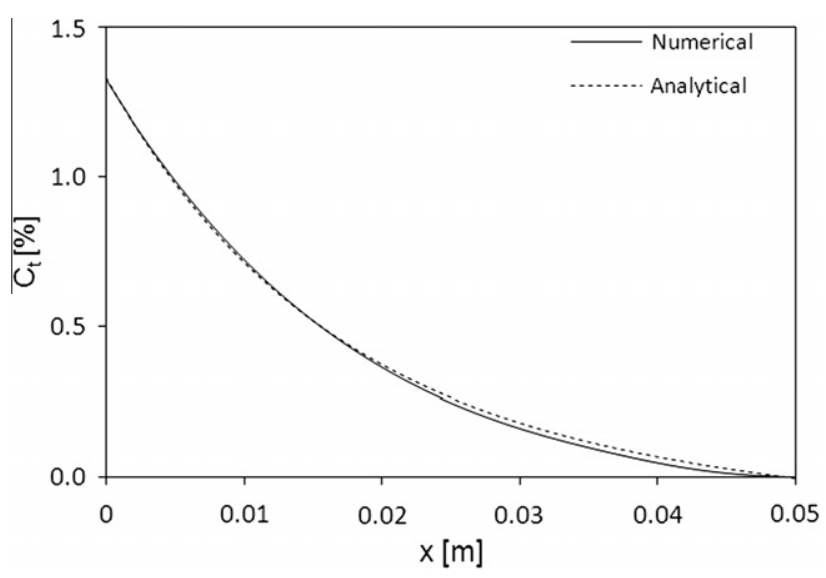

Fig. 7. Total chloride concentration profiles generated from analytical and numerical solutions $(n=1)$.

$X=1-\int_{0}^{\xi} e^{-(\tau+\xi)} J_{0}(I \sqrt{4 \tau \xi}) d \xi$

$Y=\int_{0}^{\tau} e^{-(\tau+\xi)} J_{0}(I \sqrt{4 \tau \xi}) d \tau$,

where $J_{0}(I \sqrt{4 \tau \xi})$ is the zero-order Bessel function of the first kind.

For typical experimental conditions during the RCM test and the chloride mass transfer coefficient being the limitation of the transport of chlorides (i.e. small values of $k$ ) the value of the Bessel function yields unity. With this simplification Eqs. (43) and (44) can be integrated, yielding $c$ and $C_{b}$ :

$c=c_{0}\left(1-e^{-\tau}+e^{-\tau-\xi}\right)$,

$C_{b}=C_{0} K_{b}\left(e^{-\xi}-e^{-\tau-\xi}\right)$.

\subsection{Comparison of numerical and analytical solutions}

In order to verify the validity of the numerical solution presented in Section 5.3, chloride concentration profiles generated applying both the analytical solution (Eqs. (45) and (46)) and the numerical solution (Eqs. (26) and (27)) are compared. The input parameters used for this computation are presented in Table 1 (for $\mathrm{C} 2, t=18 \mathrm{~h}$ ). The remaining parameters are selected as follows: $D_{\text {eff }}=2 \times 10^{-12} \mathrm{~m}^{2} / \mathrm{s}, \quad K_{b}=0.5 \times 10^{-3} \mathrm{dm}^{3 n} / \mathrm{g}^{n}, \quad n=1$, $k=5 \times 10^{-6} \mathrm{~s}^{-1}, \Delta x=0.0001 \mathrm{~m}, \Delta t=1000 \mathrm{~s}$ and $C_{b i}=0$. The total chloride concentration profiles resulting from Eqs. (13), (26), (27), (45), and (46) are presented in Fig. 7. The slight differences between the analytical and numerical chloride concentration profiles in Fig. 7 can be explained by the value of the Bessel function (see Eqs. (43) and (44)), which is assumed to be equal to unity, but in fact for the parameters specified above this value may vary between 1 and 1.2. Nevertheless, the agreement is satisfactory, confirming the validity of the numerical computation procedure. Therefore, for further computations presented in this paper, the numerical solution presented in Eqs. (26) and (27) is applied to experimental data.

\section{Application of the new model to experimental data}

As explained before, the non-equilibrium conditions and the Freundlich binding isotherm are proposed in the new chloride migration model, introducing the values of $k, K_{b}$ and $n$. Hence, besides the $D_{\text {eff, }}$ also these parameters can be derived for a particular concrete.

A wide database of total chloride concentration profiles obtained on concrete tested using the RCM test is presented in $[9,12,13]$. Besides the measured profiles, also many important model parameters are given (Table 1 ). Therefore, for the further investigations presented in this paper, the experimental data from above mentioned references is used.

Based on the data presented in Table 1 and on the experimental total chloride concentration profiles [9,12], the values of $k, K_{b}, n$ and $D_{\text {eff }}$ are optimized, by using Microsoft Excel Solver (Generalized Reduced Gradient Algorithm optimization method) and applying Eqs. (13), (26), and (27). In the optimization process the values of $D_{\text {eff }}$ and $k$ were restrained to be positive. The values of the binding parameters were constrained based on the data in Table 2: $n$ within the range of 0.3-0.6 and $K_{b}$ within the range of 0 and $3 \times 10^{-3} \mathrm{dm}^{3 n} / \mathrm{g}^{n}$. $C_{b i}$ was set equal to the background

Table 3

Optimized model parameters.

\begin{tabular}{|c|c|c|c|c|c|c|c|c|c|}
\hline Concrete code & $\mathrm{C} 1$ & $\mathrm{C} 1$ & $\mathrm{C} 1$ & $\mathrm{C} 2$ & $\mathrm{C} 2$ & $\mathrm{C} 2$ & $\mathrm{C} 3$ & $\mathrm{C} 4$ & C5 \\
\hline$t_{R C M}(\mathrm{~h})$ & 6 & 9 & 18 & 6 & 9 & 18 & 24 & 24 & 24 \\
\hline$D_{\text {eff }}\left(\times 10^{-12} \mathrm{~m}^{2} / \mathrm{s}\right)$ & 0.85 & 1.08 & 0.96 & 2.04 & 2.15 & 1.92 & 0.55 & 1.21 & 2.20 \\
\hline$k\left(\times 10^{-6} 1 / \mathrm{s}\right)$ & 10.54 & 7.45 & 4.55 & 5.58 & 5.32 & 2.10 & 1.90 & 1.02 & 1.05 \\
\hline$K_{b}\left(\times 10^{-3} \mathrm{dm}^{3 n} / \mathrm{g}^{n}\right)$ & 0.55 & 0.57 & 0.61 & 0.52 & 0.60 & 0.56 & 0.47 & 0.48 & 0.37 \\
\hline$n$ & 0.53 & 0.51 & 0.54 & 0.52 & 0.55 & 0.52 & 0.48 & 0.49 & 0.49 \\
\hline
\end{tabular}

(a)

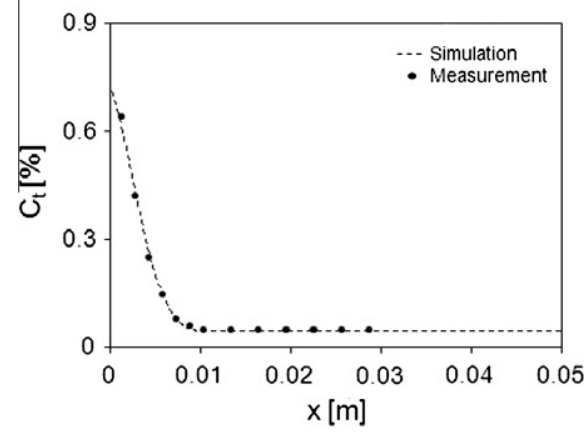

(b)

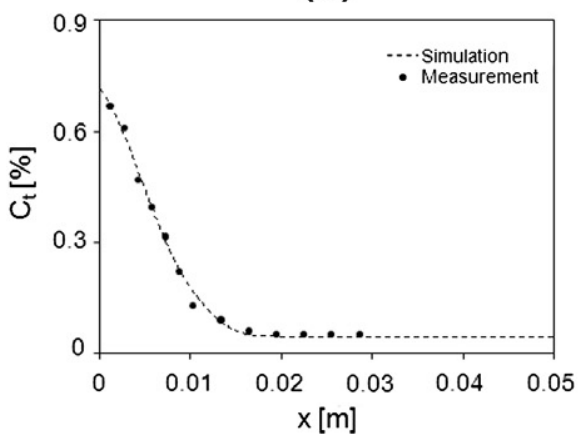

(c)

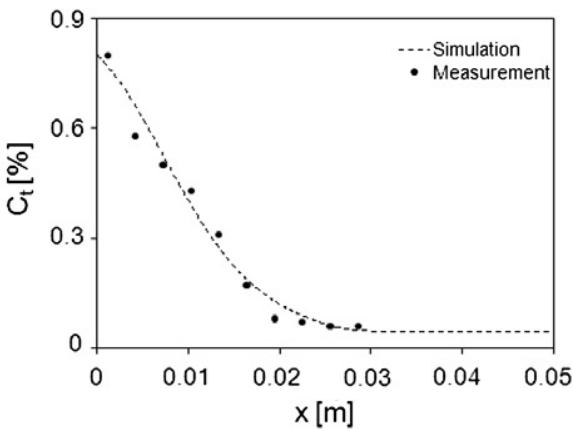

Fig. 8. Optimized total chloride concentration profiles, concrete C1 (Table 1): (a) 6 h; (b) 9 h; (c) 18 h. 
(a)

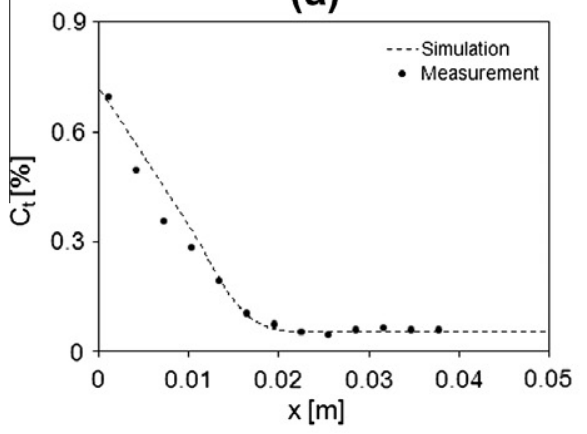

(b)

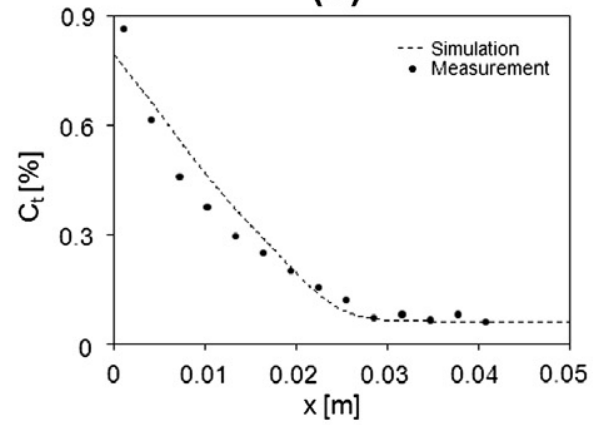

(c)

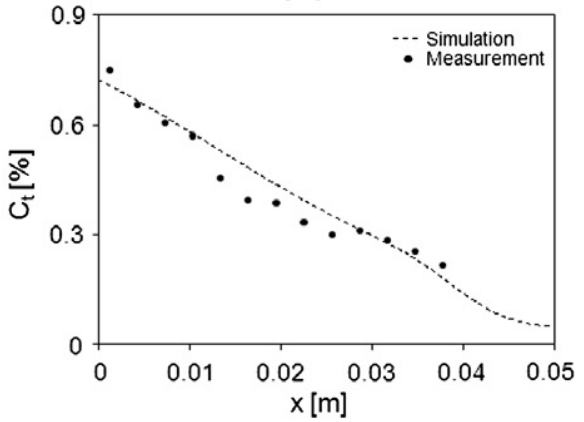

Fig. 9. Optimized total chloride concentration profiles, concrete C2 (Table 1): (a) 6 h; (b) 9 h; (c) 18 h.

(a)

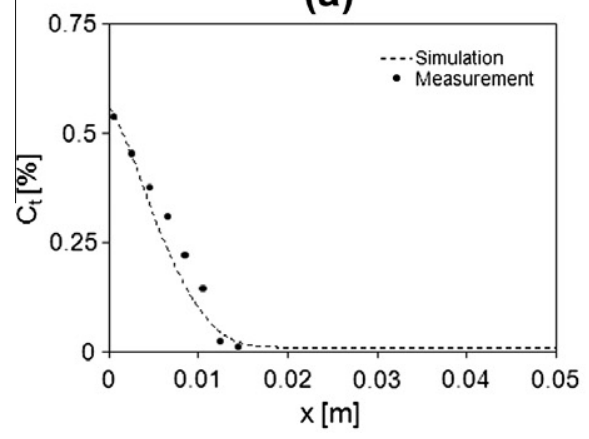

(b)

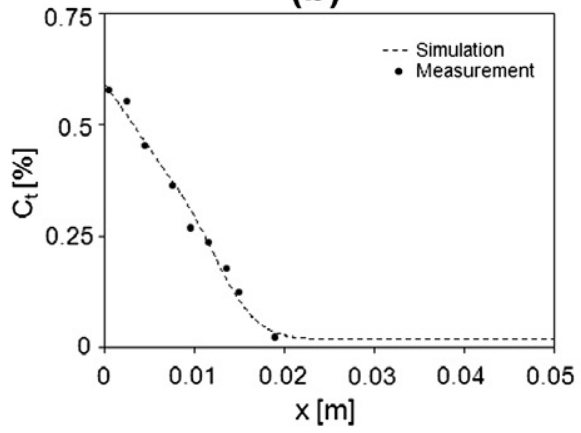

(c)

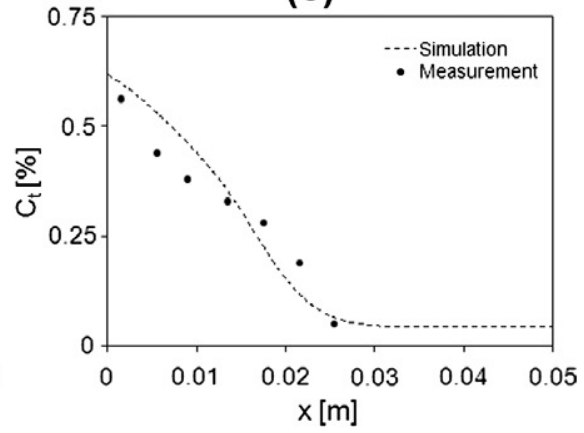

Fig. 10. Optimized total chloride concentration profiles, concretes C3, C4 and C5 (Table 1): (a) C3; (b) C4; (c) C5.

concentration measured for each analyzed profile. The initial solutions were selected in their expected orders of magnitude, as follows: $\quad D_{\text {eff }}=1 \times 10^{-12} \mathrm{~m}^{2} / \mathrm{s}, \quad k=1 \times 10^{-6} 1 / \mathrm{s}, \quad n=0.5$ and $K_{b}=0.5 \times 10^{-3} \mathrm{dm}^{3 n} / \mathrm{g}^{n}$. Finally, the total mean square error of the relative difference between the experimental and simulated total chloride concentration profiles was minimized by adjusting the values of $k, K_{b}, n$ and $D_{\text {eff. }}$. The optimized values of the parameters and simulated chloride profiles are shown respectively in Table 3 and Figs. 8-10.

When analyzing the binding coefficients $K_{b}$ and $n$ it can be noticed that the values obtained from the numerical model (Table 3 ) are in a good agreement with the values presented in Table 2, measured by speciation tests. The binding capacity $K_{b}$, which determines the maximum amount of bound-chlorides, as expected from Table 2, is found to be larger for concrete containing Cem T10 (C1, C2) than for concrete with Cem I (C3, C4 and C5). This is due to an increased $\mathrm{C}_{3} \mathrm{~A}$ content in Cem T10; the hydration products of this cement phase are capable of binding more chlorides. When comparing the values of the optimized $K_{b}$ to the experimental data presented in Table 2, it can be seen that the values optimized for concrete are about five times lower than obtained on the pastes of similar cements. These values were expected because the volume of the paste in concrete is about $1 / 5$, and only the paste can bind chlorides.

The optimum value of $n$, describing the intensity of binding and the maximum amount of bound-chlorides, is found to be in the range of $0.48-0.55$, which is also in agreement with sorption data presented in Table 2.

In none of the analyzed chloride concentration profiles the maximum total chloride concentration was achieved except for the surface layer of concrete, where the chloride bearing solution and concrete are in contact from the start of the test. This confirms that the assumption of non-equilibrium in the chloride transport model

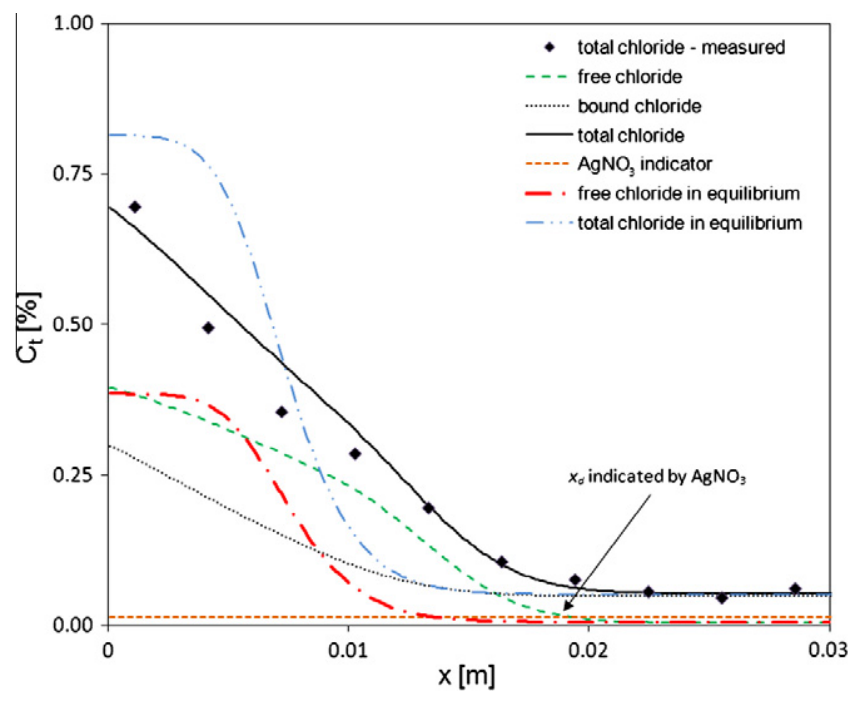

Fig. 11. Simulated chloride concentration profiles, concrete $C 2,6 \mathrm{~h}$ (Table 1 ).

presented in this paper is correct. In order to account for this phenomenon, $k$, the mass transfer coefficient, is introduced (see Section 5.1). The optimized values of $k$ decrease during the migration process, which can be observed in Table 3. One can find in Figs. 8 and 9 that the value of $k$ plays a deciding role on the shape of each profile. When the chloride mass transfer coefficient is larger, chlorides are bound faster and they do not have so much freedom to penetrate farther into the concrete, which results in a more abrupt chloride profile (e.g. see in Fig. 8a). However, when the value of $k$ becomes smaller, the mass transfer rate of chlorides becomes the limiting factor and the profile is characterized by a 
Table 4

Comparison of the diffusion coefficients.

\begin{tabular}{|c|c|c|c|c|c|c|c|c|c|}
\hline Concrete code & $\mathrm{C} 1$ & $\mathrm{C} 1$ & $\mathrm{C} 1$ & $\mathrm{C} 2$ & $\mathrm{C} 2$ & $\mathrm{C} 2$ & $\mathrm{C} 3$ & $\mathrm{C} 4$ & $\mathrm{C} 5$ \\
\hline$t_{R C M}(\mathrm{~h})$ & 6 & 9 & 18 & 6 & 9 & 18 & 24 & 24 & 24 \\
\hline$D_{\text {eff }}\left(\times 10^{-12} \mathrm{~m}^{2} / \mathrm{s}\right)$ & 0.85 & 1.08 & 0.96 & 2.04 & 2.15 & 1.92 & 0.55 & 1.21 & 2.20 \\
\hline$x_{d}$ measured $(\mathrm{mm})$ & - & - & - & - & - & - & 14.2 & 19.3 & 26 \\
\hline$x_{d}$ computed $(\mathrm{mm})$ & 8.5 & 15.7 & 26.6 & 19.3 & 27.8 & 47.5 & 14.7 & 18.3 & 27.45 \\
\hline$D_{R C M}$ (Eq. (11)) $\left(\times 10^{-12} \mathrm{~m}^{2} / \mathrm{s}\right)$ & 7.52 & 9.62 & 8.34 & 17.91 & 17.45 & 15.17 & 5.59 & 10.36 & 19.52 \\
\hline$D_{\text {eff }}($ Eq. $(22))\left(\times 10^{-12} \mathrm{~m}^{2} / \mathrm{s}\right)$ & 2.14 & 2.65 & 2.60 & 5.22 & 5.90 & 4.60 & 1.26 & 2.75 & 4.77 \\
\hline
\end{tabular}

more gradual shape such as shown e.g. in Figs. 8c and 9c. The diminishing chloride mass transfer coefficient needs further investigations, since it plays an important role in the case of chloride migration in concrete, and has not been studied yet.

The effective chloride diffusion coefficient, shown in Table 3, is obtained indirectly - from the numerical simulations, while in the traditional RCM test, the $D_{R C M}$ is computed according to Eq. (11). One can notice that there is a clear trend between the quality of concrete expressed in terms of the compressive strength (see in Table 1 ) and the optimized $D_{\text {eff. }}$ There is also a relation between the values of the $D_{\text {eff }}$ and the $w / c$ ratio: the concrete with low $w / c$ ratio $(\mathrm{C} 1, \mathrm{C} 3)$ has the lowest values of $D_{\text {eff }}$ and when the $w / c$ is increased (C2, C4 and C5) the $D_{\text {eff }}$ increases as well. Moreover, these optimized $D_{\text {eff }}$ correspond well with the values of the diffusion coefficients presented in [1] for concretes with similar $w / c$ ratios, which were measured in steady-state migration experiments.

In order to obtain the values of $D_{R C M}$ (Eq. (11)), the free-chloride profiles were simulated and therefore the free-chloride penetration depths $x_{d}$ could be estimated. In Fig. 11 examples of the simulated free-, bound- and total chloride concentration profiles are shown, including the penetration depth $\left(x_{d}\right)$ which can be indicated by the spraying method. In Fig. 11 also a free- and total chloride profile, computed for a larger value of $k\left(3 \times 10^{-5} 1 / \mathrm{s}\right)$ are shown in order to simulate the chloride profiles shape if the equilibrium could be reached faster. These equilibrium chloride concentration profiles are similar to the theoretical abrupt profiles, as can be seen in Fig. 2. One can also notice that if the free-chlorides would be instantaneously bound in concrete, the chloride penetration depth would be smaller.

Table 4 shows the optimized $D_{\text {eff, }}$, measured [9] and predicted $x_{d}$, $D_{R C M}$ calculated according to the traditional model (Eq. (11)) and the $D_{\text {eff }}$ computed from this $D_{R C M}$ (Eq. (22), assuming that $\left.D_{R C M}=D_{a p p}\right)$. The values of $D_{\text {eff }}$ calculated from the $D_{R C M}$ coefficient are larger than the values of $D_{\text {eff }}$ optimized from the new model. This can be explained by the fact that when chlorides are not bound immediately, they have more freedom to penetrate farther into concrete, as shown in Fig. 11. Thus, the traditional RCM model must give a larger value of the $D_{R C M}$ coefficient in order to account for this increased penetration depth. Meanwhile, the new model predicts lower values of the $D_{\text {eff, }}$ which correspond well with data obtained in steady-state migration tests (e.g. as shown in [1]).

\section{Conclusions}

The non-linear chloride binding isotherm and the nonequilibrium conditions between the free- and bound-chlorides are implemented in the new model for the RCM test. This model can predict the chloride transport in concrete better than the traditional model. The effective chloride diffusion coefficient as well as the binding parameters and the chloride mass transfer coefficient can be estimated from application of this new model to the experimental data. The values of the non-linear binding parameters $\left(K_{b}\right.$ and $\left.n\right)$ extracted from the new model show good agreement with experimental data presented in literature, following from sorption studies. The mass-transfer coefficient $k$ features a tendency to decrease in time during the migration test. The effective chloride diffusion coefficient $D_{e f f}$, obtained from the new model, corresponds well with experimental data found in literature for similar concretes. It has also been demonstrated that the $D_{R C M}$ calculated in the traditional way is overestimated.

The most important advantages of the RCM test are its simple test procedure, short testing duration and a good repeatability of results. In future work it will be necessary to interpret the RCM test procedure differently in order to calculate the diffusivity of chlorides in a new way, but still trying to retain these advantages.

\section{Acknowledgements}

The authors wish to express their gratitude to the following sponsors of the Building Materials research group at TU Eindhoven: Bouwdienst Rijkswaterstaat, Graniet-Import Benelux, Kijlstra Betonmortel, Struyk Verwo, Attero, Enci, Provincie Overijssel, Rijkswaterstaat Directie Zeeland, A\&G Maasvlakte, BTE, Alvon Bouwsystemen, V.d. Bosch Beton, Selor, Twee "R" Recycling, GMB, Schenk Concrete Consultancy, Intron, Geochem Research, Icopal, BN International, APP All Remove, Consensor, Eltomation, Knauf Gips, Hess ACC Systems and Kronos (in chronological order of joining) and to ir. J.J.W. Gulikers, MSc. Q.L. Yu and Dipl. Eng. M.V.A. Florea for their advice.

\section{References}

[1] Tang L. Chloride transport in concrete - measurement and prediction. PhD thesis, Chalmers University of Technology, Gothenburg, Sweden, 1996.

[2] NT Build 492. Concrete, mortar and cement-based repair materials: Chloride migration coefficient from non-steady-state migration experiments. Nordtest method, 1999.

[3] DuraCrete. Probabilistic performance based durability design of concrete structures. DuraCrete final technical report, document BE95-1347/R17, 2000.

4] Breitenbücher R, Gehlen C, Schiessl P, van den Hoonaard J, Siemens T. Service life design for the Western Scheldt Tunnel. In: 8th International conference of building materials and components 3-15, Vancouver, Canada, 1999.

[5] Andrade C. Calculation of chloride diffusion coefficients in concrete from ionic migration measurements. Cem Concr Res 1993;23:724-42.

[6] Andrade C, Sanjuan MA, Recuero A, Rio O. Calculation of chloride diffusivity in concrete from migration experiments, in non steady-state conditions. Cem Concr Res 1994:24:1214-28.

[7] Tang L, Sorensen HE. Precision of the Nordic test methods for measuring the chloride diffusion/migration coefficients of concrete. Mater Struct 2001;34:479-85.

[8] Baroghel-Bouny V, Belin P, Maultzsch M, Henry D. $\mathrm{AgNO}_{3}$ spray test: advantages, weaknesses, and various applications to quantify chloride ingress into concrete. Part 2: Non-steady-state migration test and chloride diffusion coefficients. Mater Struct 2007;40:783-99.

[9] Yuan Q. Fundamental studies on test methods for the transport of chloride ions in cementitious materials. PhD thesis, University of Ghent, Belgium, 2009.

[10] Castellote M, Andrade C, Alonso C. Measurement of the steady and nonsteady-state chloride diffusion coefficients in a migration test by means of monitoring the conductivity in the anolyte chamber. Comparison with natural diffusion test. Cem Concr Res 2001;31:1411-20.

[11] Bird RB, Stewart WE, Lightfoot EN. Transport phenomena. New York, USA: John Wiley \& Sons Ltd.; 1960.

[12] Stanish KD. The migration of chloride ions in concrete. PhD thesis, University of Toronto, Canada, 2002

[13] Stanish KD, Hooton RD, Thomas MDA. Prediction of chloride penetration in concrete, US Department of Transportation. Federal Highway Administration, FHWA-RD-00-142, 2001 
[14] Castellote M, Andrade C, Alonso C. Chloride-binding isotherms in concrete submitted to non-steady-state migration experiments. Cem Concr Res 1999;29:1799-806

[15] Castellote M, Andrade C, Alonso C. Accelerated simultaneous determination of the chloride depassivation threshold and of the non-stationary diffusion coefficient values. Corros Sci 2002;44:2409-24.

[16] Gruyaert E, Van den Heede Ph, De Beile N. Chloride ingress for concrete containing blast-furnace slag, related to microstructural parameters. In: Proceedings of the 2nd international RILEM workshop on concrete durability and service life planning, 440-448, Haifa, Israel, 2009.

[17] Zibara H. Binding of external chlorides by cement pastes. PhD thesis, University of Toronto, Canada, 2001.

[18] Justnes H. A review of chloride binding in cementitious systems. Nord Concr Res 1998;21:1-6.

[19] Yuan Q, Shi C, De Schutter G, Audenaert K, Deng D. Chloride binding of cementbased materials subjected to external chloride environment - a review. Construct Build Mater 2009;23:1-13.

[20] Glass GK, Reddy B, Buenfeld NR. The participation of bound chloride in passive film breakdown on steel in concrete. Corros Sci 2000;42:2013-21.
[21] Loser L, Lothenbach B, Leemann A, Tuchschmid M. Chloride resistance of concrete and its binding capacity - comparison between experimental and thermodynamic modelling. Cem Concr Compos 2010;32:34-42.

[22] Green DW, Perry RH. Perry's chemical engineers' handbook, 8th ed.; 2007.

23] Theissing EM, Hest-Wardenier Pv, de Wind G. The combining of sodium chloride and calcium chloride by a number of different hardened cement pastes. Cem Concr Res 1978;8:683-92.

[24] NT Build 443. Concrete, hardened: accelerated chloride penetration. Nordtest method, 1995.

[25] Narsilio GA, Li R, Pivonka P, Smith DW. Comparative study of methods used to estimate ionic diffusion coefficients using migration tests. Cem Concr Res 2007;37:1152-63.

[26] Brouwers HJH. Transport model for desorption from natural soils packed in flushed columns. Water Resour Res 1999;35:1771-80.

[27] Atkinson A, Nickerson AK. The diffusion of ions through water-saturated cement. J Mater Sci 1984;19:3068-78. 